\title{
Performance of geosynthetic reinforced wall during rainfall
}

\author{
C. Yoo ${ }^{\text {i) }}$ and S. M. Shin ${ }^{\text {ii) }}$
}

\begin{abstract}
i) Professor, Sungkyunkwan University, Department of Civil and Environmental Engineering, Jang-An Gu, Suwon, Korea; $\mathrm{Ph)82-31-290-7518;} \mathrm{Fax)} \mathrm{82-31-290-7549}$

ii) Graduate student, Sungkyunkwan University, Department of Civil and Environmental Engineering, Jang-An Gu, Suwon, Korea; Ph)82-31-290-7537; Fax) 82-31-290-7549
\end{abstract}

\begin{abstract}
Global warming has become a global issue in recent years. Korean peninsula has been no exception in terms of global warming. The direct consequence of the temperature increase due to the global warming is an increase in the annual precipitation. Since the rate and amount of precipitation has of paramount implications on short and long-term performance of geo-structures, geo-engineers should pay attention to the issue of global warming. In this paper, the results of numerical investigation on a geosynethic reinforced soil wall (GRSW) are presented. A two dimensional stress-pore pressure coupled finite element model was adopted which can realistically simulate the interaction between rainfall and a GRSW within the framework of unsaturated soil concept. Practical implications on the findings of this study will also be discussed.
\end{abstract}

Keywords: Global warming, heavy rainfall, stress-pore pressure coupled finite element analysis, geosynthetic reinforced soil wall

\section{INTRODUCTION}

The issue of global warming has now become one of the important issues that have to be tackled with urgency. Recent severe weather patterns may be highly associated with global warming (IPCC 2007). For example, during the past decade, the occurrence of locally concentrated heavy rainfall in Korea is increasing due to climate change. For example, Korean Meteorological Administration (KMA 2008) reported that the annual precipitation during last 10 years has increased from $1,200 \mathrm{~mm}$ to $1,300 \mathrm{~mm}$ on average with a continually increasing trend. The direct consequence of the temperature increase is an increase in the annual amount of precipitation (IPCC 2007).

Such a trend has brought concerns to geotechnical engineers over the rainfall-triggered geo-structure failures. From the point of GRSW stability, the issue of rainfall-triggered failure is even more becoming important since the use of on-site, marginal soil with high percentage of fines as backfill is increasing even if the soil does not meet the criteria set by the current widely accepted design approaches such as Collin (1997) and Elias and Christopher (1997).
Case histories concerning rain-triggered GRSW failure include those reported by Yoo and Jung (2007) and Yoo (2011). Yoo and Jung (2007) has presented a good case history of rainfall induced GRSW failure, based on the results of a forensic study on a $8 \mathrm{~m}$ high geosynthetic reinforced soil wall (GRSW) failure caused by heavy rainfall. According to Yoo and Jung (2007), a combination of three factors, the inappropriate design, the poorly draining backfill soil, and the heavy rainfall contributed to the wall failure.

Another example of recent GRSW wall collapse in Korea is shown in Figure 2. The 14 $\mathrm{m}$ high, two-tier GRSW was collapsed during a severe rainfall in 2007. The observed failure surface followed the typical circular pattern, passing the toe of the wall and the retained zone. A forensic study was conducted to identify the cause of the wall failure. The results indicated that the rainfall was the triggering factor although the reinforcement length was shorter than required. The GRSW failure cases presented above highlight the need to properly account for the heavy rainfall associated with climate change (Yoo et al. 2008 $\left.2008^{\mathrm{b}}\right)$. 
In this paper, the results of a numerical investigation into the effect of rainfall on the performance of a geosynthetic reinforced soil wall are presnted base on the stress-pore pressure coupled finite element (FE) analysis within the framework of transient water flow through unsaturated-saturated soils together with unsaturated shear strength of soil. Also presented are the results of a laboratory investigation into the effect of rainfall on the performance of a $1-g$ GRSW model.

\section{STRESS PORE PRESSUE COUPLED FINTIE ELEMENT ANALYSIS}

\subsection{GRSW and rainfall considered}

A $8.0 \mathrm{~m}$ high geosynthetic reinforced soil wall was considered (Figure 1). The wall is reinforced with $0.7 \mathrm{H}$ long geogrids having a long-term design strength of $10 \mathrm{kN} / \mathrm{m}$ with an axial stiffness of $\mathrm{J}=500 \mathrm{kN} / \mathrm{m}$, installed at vertical spacing of $0.4 \sim 0.6 \mathrm{~m}$. It was assumed that the wall facing consists of segmental blocks of $200 \mathrm{~mm}$ in height and 300 in depth with no batter angle.

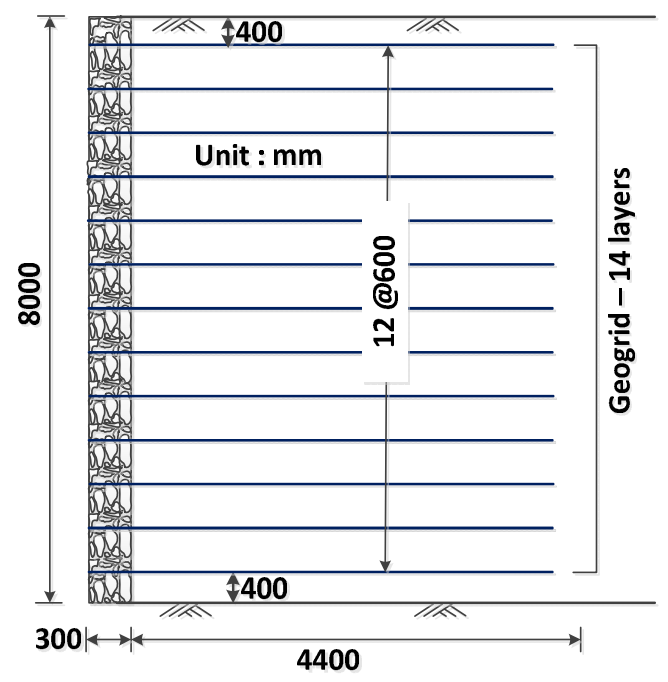

Fig. 1. Layout of wall considered.

A silty sand, SM according to the Unified Soil Classification System (ASTM D2487-90 1992), was assumed to be used as backfill Note that the silty sand is the same soil used for the wall reported by Yoo and Jung (2007) which is the marginal soil, a completely decomposed granitic (CDG) soil in nature. Table 2 summarizes the geotechnical properties of the backfill soils considered.

The stress-pore pressure coupled FE analysis involving transient water flow through unsaturated-saturated zones requires the soil's water retention characteristics by defining the relationship between the matric suction $u_{a}-u_{w}$ where $u_{a}=$ pore air pressure, $u_{w}=$ pore water pressure and the degree of saturation $s$. Figure 2 shows the soil water characteristic curve used for the backfill soil.

Table 1. Geotechnical properties of backfill soils

\begin{tabular}{cccccc}
\hline type & $\begin{array}{c}c^{\prime} \\
(\mathrm{kPa})\end{array}$ & $\begin{array}{c}\phi^{\prime} \\
\left(^{\circ}\right)\end{array}$ & $\begin{array}{c}E \\
(\mathrm{kPa})\end{array}$ & $\begin{array}{c}\gamma \\
\left(\mathrm{kN} / \mathrm{m}^{3}\right)\end{array}$ & $\begin{array}{c}k_{s} \\
(\mathrm{~m} / \mathrm{s})\end{array}$ \\
\hline $\begin{array}{c}\text { sity } \\
\text { sand }\end{array}$ & 13 & 22 & 20,000 & 18 & $5 \times 10^{-7}$ \\
\hline
\end{tabular}

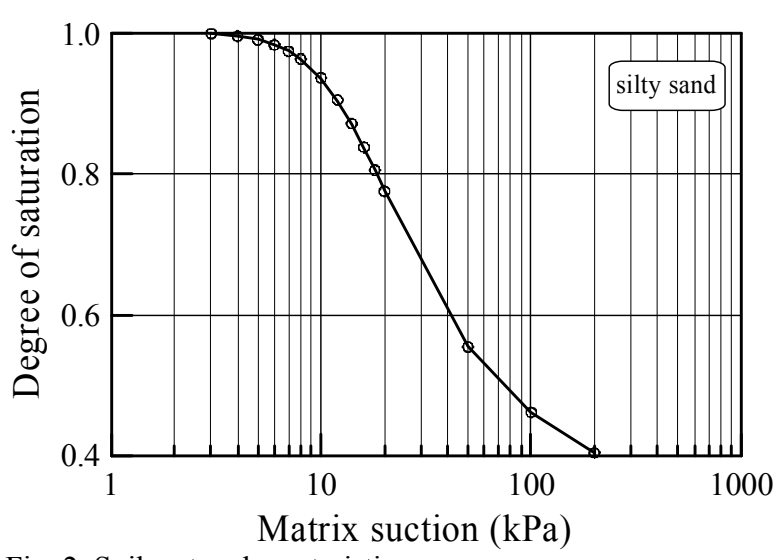

Fig. 2. Soil water characteristic curves.

Also assumed was that the permeability of unsaturated soil is $k_{w}$ can be a cubic function of degree of saturation as (Abaqus 2011)

$$
k_{w}=k_{s} s^{3}
$$

where $k_{s}=$ saturated coefficient of permeability.

In this study, it was assumed that a total of 300 $\mathrm{mm}$ of rainfall occurs over a period of 30 days, which yields a rainfall intensity of $I_{r}=0.01 \mathrm{~m} /$ day . Also considered was an antecedent rainfall of $500 \mathrm{~mm}$ over a 6 month period. The modeling of the antecedent rainfall was necessary to create an initial pore pressure condition to be used as a starting point for the subsequent analysis considering the main rainfall event. The importance of modeling of an antecedent hydrology condition on any subsequent hydrology modeling has been fully discussed by Blake et al. (2003).

\subsection{Finite element model}

In the finite element modelling, the wall components, i.e., the wall facing, the backfill soil, and the reinforcement layers, were explicitly modelled together with the facing-soil interface as shown in Figure 3. Also included in the finite element model is the foundation supporting the wall. As shown, the soil region including the foundation and the facing blocks were discretized using the eight node stress pore pressure element with reduced integration (CPE8RP) while the 
reinforcements using three node bar element (T3D2). The finite element model consists of approximately 2800 nodes and 2900 elements.

With respect to the constitutive modeling, the backfill soil was assumed to be a non-dilatant elasto-plastic material, conforming to the MohrCoulomb failure criterion together with the nonassociated flow rule proposed by Davis (1968). The wall facing was assumed to behave in a linear elastic manner with the elastic constants of Young's modulus (E) and Poisson's ratio ( $v$ ) of $100 \mathrm{MPa}$ and 0.25 , respectively. The foundation was assumed to be a competent linear elastic material having $E=100 \mathrm{MPa}$ and $v=0.3$. The geogrid reinforcement was also assumed to behave in a linear elastic manner, having an axial stiffness of $\mathrm{J}=500 \mathrm{kN} / \mathrm{m}$.

With reference to Figure 3, the lateral displacements at the boundaries $\mathrm{AB}$ and $\mathrm{CDE}$ were restrained while pin supports were assumed at the bottom boundary BC. In a stress-pore pressure coupled FE analysis, hydraulic boundary conditions need to be prescribed in addition to the displacement boundary conditions. A drainage boundary is defined by prescribing a drainage-only flow condition to candidate drainage boundaries, such as AG and FG. No-flow boundary condition was assumed at the boundaries $\mathrm{AB}$ and $\mathrm{CDE}$.

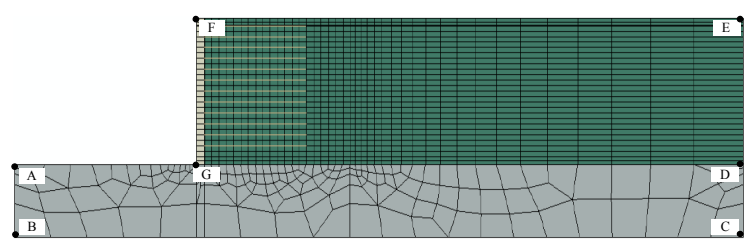

Fig. 3. Finite element model adopted.

\subsection{Construction and rainfall infiltration modelling procedure}

The initial stress and pore pressure conditions were first achieved before simulating the rainfall infiltration in a time domain. The initial stress condition of the foundation portion was first created by turning on the gravity of the zone ABCDG. The actual wall construction process consisting of placing the facing block, backfill, and the reinforcement was then closely simulated in a series of static analysis. Note that the $8.0 \mathrm{~m}$ high wall was constructed in 16 steps with an average fill height of approximately $0.5 \mathrm{~m}$. The initial pore water pressures for the backfill and the foundation soil were assigned with due consideration of the SWCCs together with an assumed initial degree of saturation.

Upon simulating the wall construction, the antecedent rainfall of $I_{r}=0.0028 \mathrm{~m} /$ day was first simulated over a 6 month period in the stress- pore pressure coupled analysis in order to achieve the pre-rainfall pore pressure condition in the backfill soil. The coupled analysis was then continuously carried out in the following steps for the mail rainfall event, imposing the flow velocity, corresponding to the rainfall intensify of $I_{r}=0.01 \mathrm{~m} /$ day, normal to the surface boundaries EF.

\section{EFFECT OF RAINFALL ON WALL PERFORMANCE}

\subsection{Wall deformation}

The progressive developments of the wall displacements are illustrated in Figures 4 and 5. As shown in Figures 4 and 5, it is seen that the wall displacement continuously increases after the end of wall construction as great as $90 \mathrm{~mm}$ at the location $1 / 3 \mathrm{H}$ above the wall base. Such an additional wall displacement is considerably larger than that occurs during the wall construction.

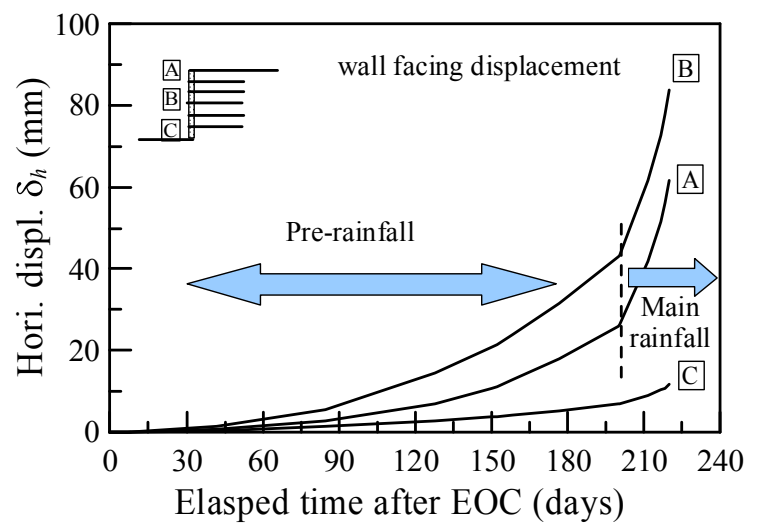

Fig. 4. Progressive development of wall deformation.

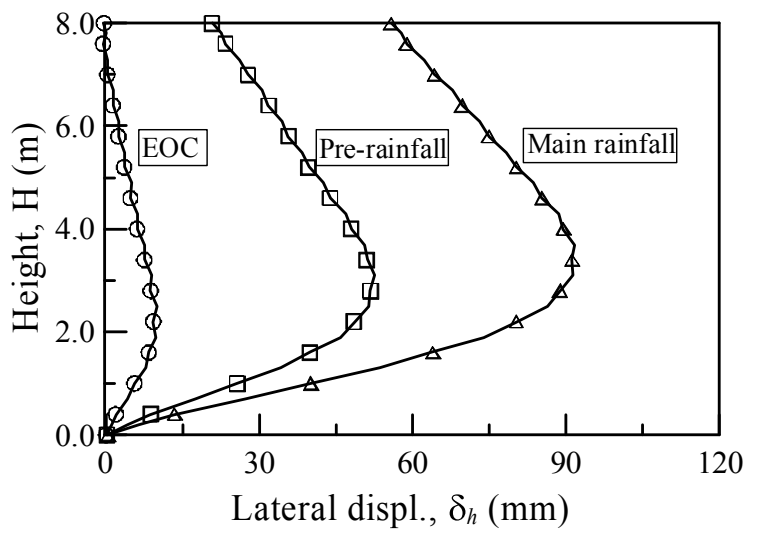

Fig. 5. Wall displacement profiles at various steps.

The increases in wall deformation are mainly due to the decrease in shear strength caused by decreases in matric suction due to the rainfall as illustrated in Figure 6 which shows the changes in 
pore pressures within the reinforced zone at different location.

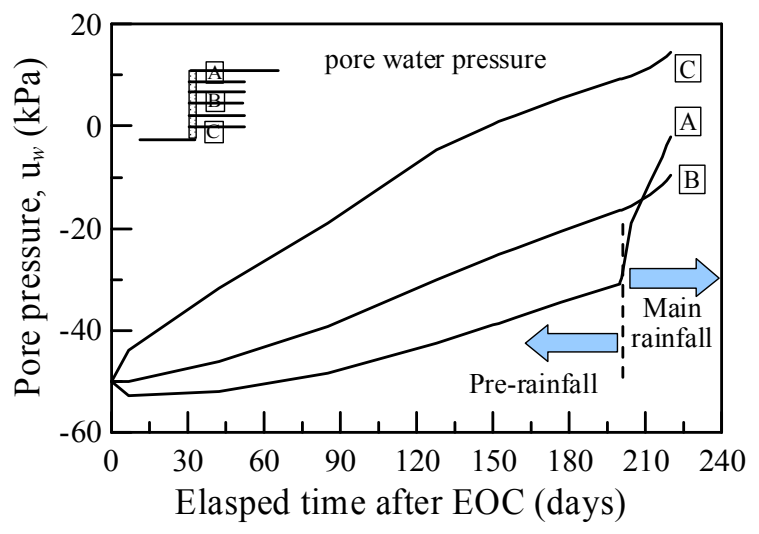

Fig. 6. Variation of matric suction in backfill.

\subsection{Reinforcement force}

The increases in the wall displacement impose additional loads in the reinforcement as shown in Figure 7. As can be seen in this figure, the reinforcement loads tend to continually increase during the rainfall with a maximum increase as great as $8 \mathrm{kN} / \mathrm{m}$. For walls with marginal factor of safety against tensile overstress, such an increase may cause long term wall instability problem.

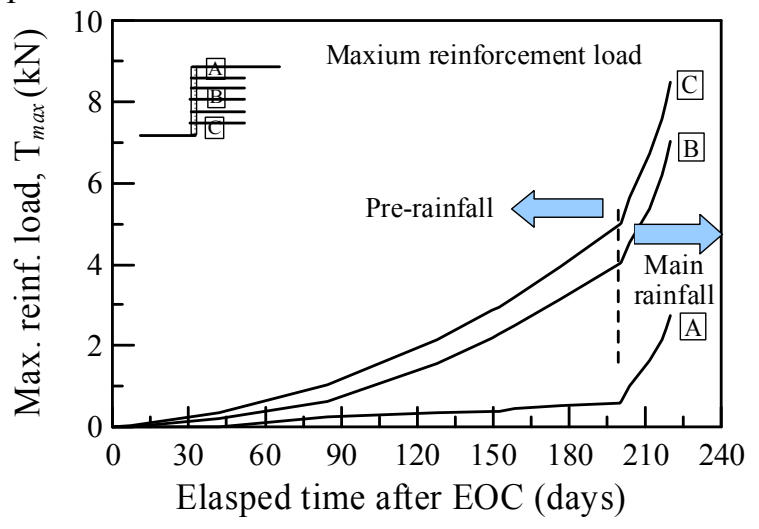

Fig. 7. Development of reinforcement load $\llcorner$ during rainfall infiltration.

\section{1-G LABORATORY INVESTIGATION}

\subsection{Test configuration}

A series of reduced scale model tests were performed using $0.5 \mathrm{~m}$ high reduced scale model GRSWs constructed in a test box, having dimensions of $0.9 \mathrm{~m} \times 0.4 \mathrm{~m}$ in plan and $0.6 \mathrm{~m}$ in height, made of $2 \mathrm{~cm}$ thick Plexiglas. The test box was made sufficiently rigid to maintain the plane-strain condition during test. The wall facing, made of $0.5 \mathrm{~cm}$ thick Plexiglas, was hinged at the bottom of the test box so as to allow lateral displacement to occur during the wetting and drying process.

Decomposed granite soils (DCG) in Korea, classified as SP as per ASTM 2487 (ASTM 1992) was used as backfill soil. DCG, a non-plastic poorly-graded sand, is commonly used as backfill soil in Korea, and has the effective size $\left(D_{10}\right)$, uniformity coefficient $\left(C_{u}\right)$, and coefficient of curvature $\left(C_{c}\right)$ of $0.36 \mathrm{~mm}, 5.3$ and 1.1 , respectively. The soil was compacted to $70 \%$ of its maximum unit weight $\left(19 \mathrm{kN} / \mathrm{m}^{3}\right)$ to create reinforced as well as retained zones. The estimated effective internal friction angle $\left(\phi^{\prime}\right)$ using a series of consolidated-undrained (CU) triaxial compression tests with pore pressure measurements at a density corresponding to the ascompacted state was determined as approximately $35^{\circ}$ with a shear stress intercept of $8 \mathrm{kPa}$.

A non-woven geotextile was used as reinforcement. Note however that the tensile strength of the non-woven geotextile was intentionally reduced by creating $5 \mathrm{~mm} \times 5 \mathrm{~mm}$ square holes (Figure 8 ) to have an ultimate tensile strength of $3.8 \times 10^{-2} \mathrm{kN} / \mathrm{m}$.

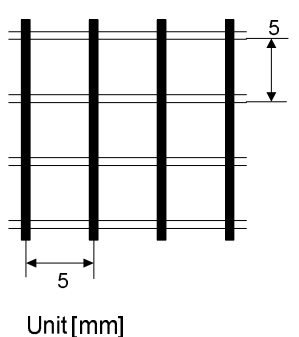

(a) Grid size

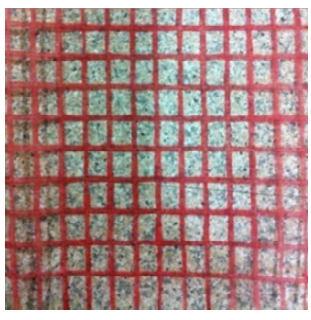

(b) photo
Fig. 8. Model geotextile reinforcement.

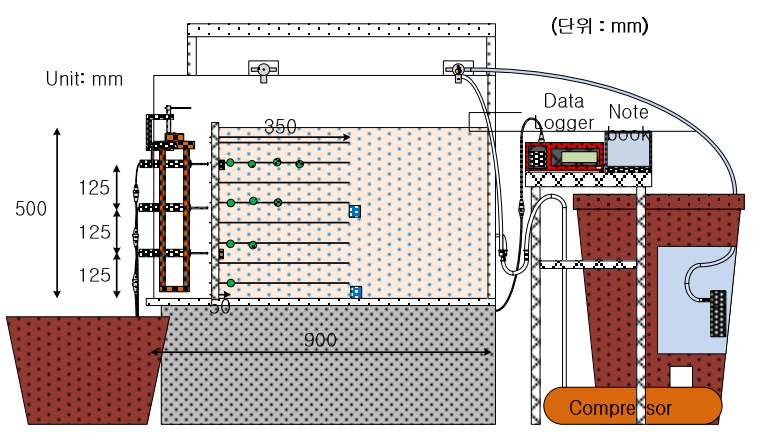

Fig. 9. Model wall and rainfall simulator.

Figure 9 shows the model wall and the rainfall simulator. As shown, six layers of reinforcement, $35 \mathrm{~cm}$ in length each, were placed at a vertical spacing of $6 \mathrm{~cm}$ (Figure 9). The reinforcement layers were firmly connected to the wall facing by bolting. In the test, two rainfall intensities $\left(I_{r}\right)$ were considered, i.e., $18.7 \mathrm{~mm} / \mathrm{h}$ and $56.2 \mathrm{~mm} / \mathrm{h}$ for a given total precipitation of $450 \mathrm{~mm}$. These rainfalls were applied in three cycles of wetting 
and drying to simulate the natural weather condition. The duration of the rainfall for the case with $I_{r}=18.7 \mathrm{~mm} / \mathrm{h}$ was therefore 24 hours while 8 hour duration was used for the case with $I_{r}=56.2 \mathrm{~mm} / \mathrm{h}$. The rainfall was simulated by spraying water at the top of the backfill using spray guns with $15 \mathrm{HP}$ compressor and a $20 \mathrm{~W}$ water motor .

The performance of the model GRSW under a series of wetting and drying cycles was evaluated in terms of wall facing displacements, pore water pressures, and reinforcement strains.

\subsection{Wall performance during rainfall}

Figures 10 and 11 show the measured wall displacements and the reinforcement strains for the case with a rainfall intensity of $18.7 \mathrm{~mm} / \mathrm{h}$. Note that the total rainfall was kept same at $450 \mathrm{~mm}$ as in the case of $I_{r}=56.2 \mathrm{~mm} / \mathrm{h}$ but with a longer wetting period of 24 hours. The discrepancies in the wall performance between the two cases can therefore be thought to stem from the rainfall intensity.
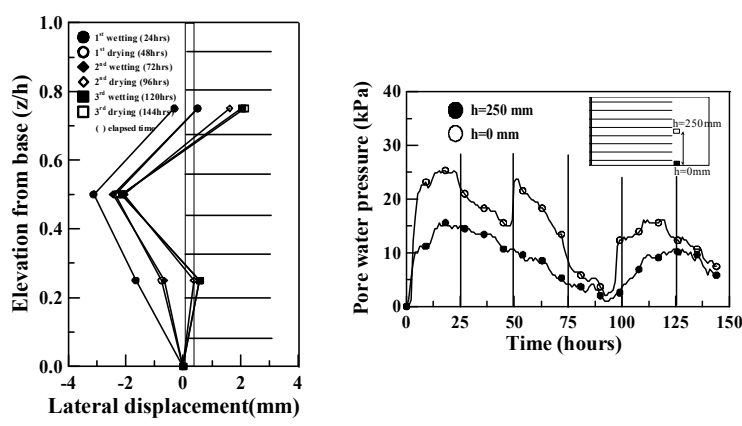

(a) wall displacement

(b) pore water pressure

Fig. 10. Wall displacement and pore pressure $\left(I_{r}=18.7 \mathrm{~mm} / \mathrm{h}\right)$.

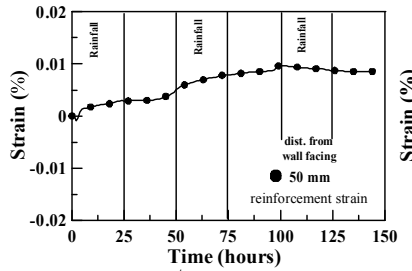

(a) $1^{\text {st }}$ layer

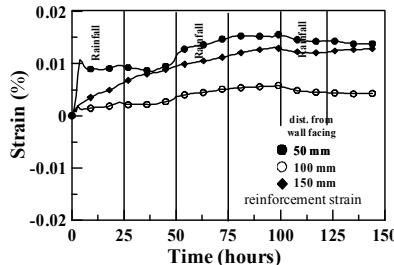

(c) $3^{\text {rd }}$ layer

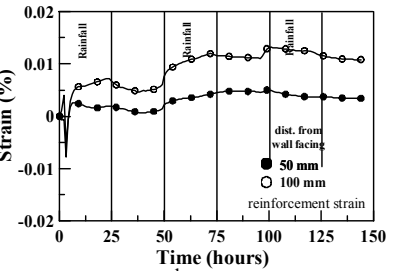

(b) $2^{\text {nd }}$ layer

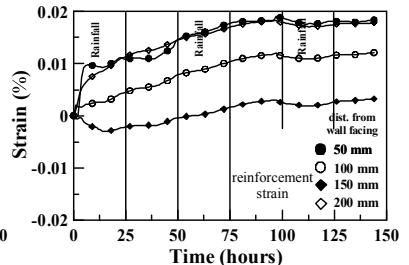

(d) $4^{\text {th }}$ layer
Fig. 11. Reinforcement strains $\left(I_{r}=18.7 \mathrm{~mm} / \mathrm{h}\right)$.

The direct comparison between the two cases reveals that the case with the smaller rainfall intensity but with the longer duration generally induces larger wall displacements and reinforcement strains except for the pore water pressure measured at the back of reinforced zone. Considering the backfill soil being a high permeability soil, these results contradict those reported by Cai and Ugai (2005) as well as Rahardjo et al. (2007) which were based on a numerical study. A further study is therefore warranted to confirm the effect of rainfall intensity. It can however be stated that the rainfall intensity is a controlling factor for the performance of a GRSW during rainfall infiltration as reported by Rahardjo et al. (2007) in their study concerning natural slopes.

\section{CONCLUSIONS}

In this study, a numerical investigation on the effect of rainfall on the stability of an $8 \mathrm{~m}$ high reinforced earth wall was conducted. The numerical investigation involved using the stresspore pressure coupled finite element formulation that can consider the transient infiltration of rainfall within the framework of unsaturated shear strength.

The results indicate that the geosynthetic reinforced soil wall backfilled with a marginal soil can experience significant increases in wall displacement and reinforcement loads, indicating that heavy rainfalls may induce instability problems for geosynthetic reinforced soil walls with marginal factor of safety when using soils with high percentage of fines. It is therefore important to not to use marginal soils to ensure long term stability.

A 1-g laboratory investigation also revealed that the cycles of wetting and drying associated with a heavy rainfall may induce additional wall displacement and reinforcement strains in GRSWs. Such trends have significant implications to GRSWs with marginal factor of safety in terms of long-term performance.

\section{ACKNOLEDGMENTS}

This work was supported by the National Research Foundation of Korea (NRF) grant funded by the Korea government (MSIP) (No. 2014004636). The financial support is gratefully acknowledged. The laboratory tests were performed by Mr. Dong-Wook Jang.

\section{REFERENCES}

1) Abaqus, Inc. (2011): Abaqus users manual, Version 6.11.

2) ASTM (1992): Standard test method for classification of soils for engineering purposes. ASTM D2487-90, 
Annual Books of ASTM Standards, West Conshohocken, PA., 4.08, 326-336.

3) Blake, J.R., Renaud, J.-P., Anderson, M. G., and Hencher, S. R. (2003): Prediction of rainfall-induced transient water pressure head behind a retaining wall using a high-resolution finite element model, Computers and Geotechnics, 30, 431-442.

4) Cai, F. and Ugai, K. (2005): Numerical Analysis of Rainfall Effects on Slope Stability, International Journal of Geomechanics,4(2): 69-78.

5) Collin, J. (1997): Design Manual for Segmental Retaining Walls, $2^{\text {nd }} E d$, National Concrete Masonry Association (NCMA), Virginia, USA.

6) Davis, E. H. (1968): Theories of plasticity and the failure of soil masses." Soil mechanics: Selected topics, Butterworth's London, 341-380.

7) Elias, V. and Christopher, B.R. (1997): Mechanically Stabilized Earth Walls and Reinforced Soil Slopes, Design and Construction Guidelines, FHWA Demonstration Project 82, FHWA, Washington, DC, FHWA-SA-96-071.

8) IPCC (2007-05-04): "Summary for Policymakers" (PDF). Climate Change 2007: The Physical Science Basis. Contribution of Working Group I to the Fourth Assessment Report of the Intergovernmental Panel on Climate Change. http://ipccwg1.ucar.edu/wg1/Report/AR4WG1_Print_SPM.pdf.

9) Korean Meteorological Administration (2008): Report on Climate Change and Mitigation: Dept. of Climate Change Response: Climate Change Information Center, (in Korean).

10) Rahardjo, H., Ong, T.H., Rezaur, R.B., and Leung, E.C. (2007): Factors Controlling Instability of Homogeneous Soil Slope under Rainfall, Journal of Geotechnical and Geoenvironmental Engineering, 133(12), 1532-1543.

11) Yoo, C. and Jung, H.Y. (2007): Case History of Geosynthetics Reinforced Segmental Retaining Wall Failure, Journal of Geotechnical and Geoenvironmental Engineering, 132(12), 1538-1548.

12) Yoo, C., Kim, S.B., and Jung, H.S. (2008a): A numerical investigation on effect of vertical drainage system on geosynthetic reinforced soil wall during rainfall, Journal of Korean Geotechnical Engineering, 24(5), 99-106.

13) Yoo, C., Kim, S.B., and Han, J.Y. (2008b): A numerical investigation on stability of geosynthetic reinforced soil wall during rainfall, Journal of Korean Geotechnical Engineering, 24(12), 1-12. 